\title{
UNA INTRODUCCIÓN A LA ESTÉTICA MODAL
}

\author{
Introducing modal aesthetics
}

\section{Jordi Claramonte Arrufat \\ Universidad Nacional de Educación a Distancia (UNED), España.}

RESUMEN: Este artículo trata de precisar aquello que tienen en común las obras de arte clásicas, las intervenciones de arte de contexto y los fusiles de asalto. Mi propuesta es que las tres tienen que lograr un compromiso entre volumen de fuego, precisión de tiro y costes de producción. $\mathrm{O}$, si se prefiere una terminología más pacífica, los tres ponen de manifiesto un modo de relación, un equilibrio dinámico entre lo que cada cual tiene que hacer, lo que puede hacer y lo que hace. Entre lo necesario, lo posible y lo efectivo.

Palabras Clave: necesidad, posibilidad, efectividad, arte, intervención, cismundaneidad.

RESUM: Aquest article tracta de precisar el que tenen en comú les obres d'art clàssiques, les intervencions d'art de context i els fusells d'assalt. La meua proposta és que els tres han d'aconseguir un compromís entre volum de foc, precisió de tir i costos de producció. $\mathrm{O}$, si es prefereix una terminologia més pacífica, els tres posen de manifest una manera de relació, un equilibri dinàmic entre allò que cadascú ha de fer, el que pot fer i el que fa. Entre el necessari, el possible i l'efectiu.

Paraules clau: necessitat, possibilitat, efectivitat, art, intervenció, cismundanitat.

ABSTRACT: This article attempts to specify the commonalities between classical works of art, 'artivist' interventions, and assault rifles. I suggest that 
all three are a kind of compromise between firepower, accuracy/range and performance in real combat conditions. Or, in more peace-loving terminology, the three of them display a 'mode of relation', a kind of dynamic equilibrium between what each of them has to do, what it can do and what it finally does. That is, between Necessity, Possibility and Actuality.

KEYWORDs: necessity, possibility, actuality, artwork, intervention, cismundane.

cada generación le corresponde dar cuenta de sus luchas, de la ración de
despropósitos con que se encontró y de los modos en que, mejor o peor, pudo lidiar con ellos. No hay otra.

A mi generación le tocó, para empezar, todo el tema de la Insumisión al Servicio Militar, en oposición a un ejército que creíamos - bendita ingenuidad- que era de los últimos vestigios que había dejado el franquismo. También nos tocó empezar a plantarle cara a procesos de especulación urbanística que parecían salir de la nada, que tenían el poder de hacer inviable algo tan básico como vivir uno en su casa y que acababa por expulsar de los centros de las ciudades a todos aquellos que no tuvieran sueldos por encima de la media...

A mediados de los noventa, sin acceso generalizado a internet y sin lo que hoy llamamos redes sociales, lo que no «salía» en los medios de comunicación mayormente no existía. Así que no hubo más remedio que arremangarse y ponerse manos a la obra con la tarea de hacer existir aquellas movilizaciones en que andábamos liados, recurriendo para ello a maniobras comunicativas del más diverso pelaje.

El recurso a algunas formas de arte cercanas a la performance y las intervenciones en espacios públicos apareció como una forma potente no sólo de dar visibilidad a las luchas, sino de plantearlas con algo menos de furor apostólico del que era habitual en la izquierda de entonces — que no en la de ahora, como es notorio. 
La forma en que recurríamos a recursos y lenguajes artísticos en colectivos de acción directa como La Fiambrera Obrera, SCCPP.org (Sabotaje contra el Capital Pasandoselo Pipa) o YoMango ${ }^{1}$ implicaban, como se deja suponer ya sólo con la elección de los nombres, una manera de entender lo estético y lo político en la que la ironía, la capacidad de juego y el gusto por la complejidad se daban por supuestas y marcaban profundamente el concepto mismo de arte que nos manejábamos: lo artístico en nuestro caso no podía reducirse a algo que cuadrara con los formatos establecidos ni mucho menos podía depender de su aceptación por parte de unas instituciones artísticas que aun tardarían unos cuantos años en verle el glamour a esto de las intervenciones artístico-políticas.

El caso es que ya entonces, en los textos «teóricos» que me tocó escribir para los colectivos en que andaba, tuvimos que empezar a abordar la cuestión de qué era aquello que estábamos haciendo, en qué sentido era una acción política y en qué sentido era, a la vez seguramente, una maniobra que reivindicaba la autonomía mediante la que lo estético toma vuelo y se distancia de los diferentes catecismos en boga a cada momento para reafirmar el derecho a disentir, a vivir a la altura de nuestras propias exigencias. Y debió ser entonces, hacia mediados o finales de los 90, que tirando de maestros como John Berger o Michel de Certeau², empezamos a pensar que aquello que hacíamos no podía ser entendido puramente como una obra de arte, pero que tampoco ganábamos nada con considerarlo sólo como una maniobra de activismo. Nos gustaba pensar que lo relevante de aquello que hacíamos era cierto modo de hacer lo que tuviéramos que hacer, algo que ya entonces llamamos un «modo de relación».

Con ello seguramente lo que queríamos destacar es que lo importante no era sólo aquello que hacíamos, que obviamente tenía su peso, sino que queríamos pensar — sobre todo- en cómo lo hacíamos, el «modo» desde el cual

1. Lo significativo es que otro tanto estaba sucediendo en Francia con Ne pas plier, en Alemania con Kein Mensch ist Illegal, en el Reino Unido con Reclaim the Streets o en EEUU con RtMark (que luego serían los YesMen). Toda una ola de performatividad estética aplicada a lo político. Pueden verse más detalles en: Claramonte, Jordi: Arte de Contexto, Nerea, Donostia, 2011.

2. Michel de Certeau había publicado en 1967 sus «Manieres de faire» que no serían traducidas al inglés hasta 1992 más o menos y que nosotros tradujimos parcialmente al español. John Berger llevaba también años hablando de sus «Ways of seeing». 
dábamos cuenta del mundo y los follones en los que nos metíamos. Nos parecía que eso, el modo de relación específico en que nos movíamos, era a la vez lo que nos distinguía y lo que nos permitía acoplarnos con los demás, era la clave de nuestra «eficiencia» estética y política, y era — por supuesto — lo que podíamos estar aportando al común del que éramos parte.

Y claro, no se trataba sólo de que, dada una tarea, ésta pudiera acometerse de un modo u otro: muchas veces era justo el modo de relación el que «creaba» la tarea o el que nos permitía verla, y no sólo la tarea sino también los medios para llevarla a cabo e incluso los valores $^{3}$ desde los cuales dicha tarea aparecía como necesaria y eventualmente bien resuelta.

De esto la estética clásica sabe mucho, no en balde el nombre más antiguo que tenemos para aludir a estos modos de hacer es el de poéticas, que no significa otra cosa que «haceres» ${ }^{4}$

Todo ello tiene consecuencias que nos pueden acabar alejando bastante de lo que han sido algunas de las malas inteligencias más arraigadas en nuestra cultura intelectual. Para empezar, las poéticas, como los modos de relación, no han podido nunca resolverse en los torpes términos de sujeto y objeto. No podíamos decir que el sujeto $\mathrm{S}$ llegaba y manipulaba a placer al objeto $\mathrm{O}$, porque muy a menudo el sujeto y el objeto parecían coproducirse - como decía el astuto Deleuze, el de los pies ligeros, al hablar del agenciamiento ${ }^{5}$ jinete-estribo - necesitándose uno al otro para existir incluso.

Por descontado, todo este frente presentaba problemas de claro calado ontológico: ¿íbamos a sostener que eran nuestros modos de relación los que creaban el mundo? ¿O sostendríamos por el contrario que el mundo era completamente impermeable a los modos de relación que éramos capaces de desplegar? Los idealistas de toda la vida y el materialismo más ramplón se habían

3. Más abajo hablaremos de valores. Ya se que es una palabra poco habitual en el pensamiento contemporáneo, pero de la mano de Hartmann y Morawski quizá haya que darle vuelta y vuelta a la cuestión.

4. Hannah Arendt ha hecho una de los estudios más hermosos sobre los matices del «hacer». Entre ellos el «poiein» alude a un hacer claramente performativo, que construye su propio quehacer y los medios que precisa.

5. Puede verse una exposición muy clarificadora de dicho concepto en: Deleuze, Gilles y Parnet, Claire: Dialogues, Columbia University Press, New York, 1989. 
puesto de acuerdo para dejarse los dientes en esos tropiezos... y nosotros le teníamos cariño a nuestra dentadura intelectual.

Así que nos harían falta categorías específicas que nos permitieran entender cómo era que - aunque el mundo ya estaba ahí — cada modo de relación suscitaba una distribución de entes diferente y en cierta medida contribuía a «cambiarlo».

Haber, lo que se dice haber, sólo hay un mundo, pero sin duda éste no era del todo el mismo cuando un grupo de parados y paradas, que hasta entonces eran sólo números en las cuentas del INEM (Instituto Nacional de Empleo, España), se organizaban y tomaban las calles y de paso sus propias vidas. Ésos eran los modos de relación que nos interesaban y parecía que la manera en que las prácticas artísticas habían procedido —incluso las más clásicasnos podía ayudar a entender esto...

Para ello teníamos que comprender bien la dinámica interna de eso que Lukács llamaba «medios homogéneos» ${ }^{6}$ y que parecían ser las unidades mismas con las que se podía concebir un modo de relación en toda su gloria y contribuir con ello a construir autonomía ${ }^{7}$ y dar su poco de dignidad a nuestras propias vidas.

La cuestión entonces empezaba a ser la que nos llevaba a preguntarnos de qué estaban hechos los modos de relación. Qué había en su fábrica que permitía que se volvieran contagiosos, que resultaran apropiables y adaptables a las más diversas circunstancias, de forma que incluso poéticas concebidas hacía cientos de años o creadas en la más absoluta de las soledades pudieran encontrar resonancia en nosotras y mostrarse fértiles en nuestro quehacer.

6. Lukács, Gyorgy: Estética, Tomo II, Grijalbo, Barcelona, 1966.

7. La consistencia de esa autonomía y las diferentes versiones de la misma que se habían ido mostrando en la historia del pensamiento estético desde la ilustración hasta las versiones más fofas de la postmodernidad fue algo que me preocupó hasta tal punto que le dediqué una tesis doctoral y su correspondiente libro-secuela: La república de los fines. 
Estaba claro que ni las poéticas ni los modos de relación sucedían como episodios del todo aislados: tanto los modos de organizar sonidos, como movimientos o ideas parecían seguir patrones $^{8}$ que se reiteraban en diferentes momentos históricos y en diferentes contextos sociales. Todo era como si por debajo y por encima de nuestros modos de hacer hubiera un vasto procomún que nos englobara y nos explicara en cierta forma en la medida en que nos afectaba.

Así las cosas no es de extrañar que el siguiente paso conceptual que dimos en el camino que nos ha conducido a este libro sucediera, precisamente, en el Laboratorio del Procomún y más en concreto en el grupo de investigación sobre «Estéticas y Políticas del procomún». Aquí tocaba ir ya mucho más lejos y pensar con más amplitud de miras que la que ya nos hacía falta con las prácticas activistas en las que habíamos estado implicados. Aquí había que ponerse en la piel de la gente que hacía flamenco o urbanismo participativo9 ... Había que ser capaz de abarcar prácticas con una tradición milenaria como el wu shu chino y otras que apenas estaban esbozándose, como el parkour.

Sabíamos que había algunos de estos modos de relación, los más antiguos o vinculados a tradiciones que tenían mucho de lo que Vigotsky llamaba imaginación cristalizada. Se trataba de prácticas que sin estar en absoluto congeladas, se presentaban como poéticas dotadas ya de algo así como un repertorio relativamente estable de formas, un repertorio que daba cuenta de aquellos matices de la experiencia, aquellas áreas de la sensibilidad que abarcaba la poética en cuestión y de los que podía dar cuenta.

Pero por otra parte el procomún estético era incomprensible sin otras poéticas que, quizá debido a su relativa novedad tenían más de lo que Vigotsky hubiera llamado «inteligencia fluida», dependiendo en un grado superior de las variaciones y tanteos que sus usuarios hacen en función de su ingenio, de los talentos o las disposiciones con que cuentan.

8. La noción de patrón en Estética debe mucho a su exposición en: Alexander, Christopher: A pattern language, Oxford University Press, New York, 1977.

9. O ambas cosas juntas como Curro Aix y Santiago Barber, mis colegas de la Fiambrera en Sevilla. 
Así las cosas, los más diversos modos de relación parecían poder distribuirse según mostraran una mayor afinidad hacia lo que llamaríamos el polo de lo repertorial o el polo de lo disposicional. Sin duda ningún modo de relación quedaría enteramente decantado de uno o del otro lado, sino que más bien lo que encontrábamos era que podíamos entender cualquier poética, cualquier modo de relación como un concreta - aunque variable - proporción, una aleación ${ }^{10}$ de inteligencia cristalizada e inteligencia fluida, una mezcla en la que quizás predominaría más el cuidado de un repertorio ya relativamente logrado o quizás las variaciones disposicionales que podían aun estarlo constituyendo.

Eso sí, ningún modo de relación, ningún equilibrio entre repertorio y disposiciones sucedía en el vacío, aislado de otros mil equilibrios que podían estar fraguándose al mismo tiempo. Es más, cómo fueran dichos equilibrios finalmente, si es que eran siquiera planteables, era algo que excedía al limitado marco de cada poética: los artesanos de Arts \& Crafts a finales del XIX o los campesinos de Chiapas a finales del xx no dependían sólo de su propio equilibrio modal, sino que estaban insertos, tramados en una lucha incesante con un paisaje complejo que les precedía y les situaba, un paisaje que a su vez - de eso se trataba - podía ser cambiado por ellos, pero con el que obviamente había que contar. Todo modo de relación aparecía entonces como la articulación de un repertorio con unas disposiciones puesto en un paisaje.

Así, sin demasiada violencia, nos vimos pertrechados de tres categorías modales: ${ }^{11}$ lo repertorial, lo disposicional y el paisaje... que no sólo daban cuenta de la contextura de los modos de relación que estábamos investigando, sino que nos permitían un acercamiento crítico a los mismos.

10. Al igual que sucede con una aleación de metales como la del bronce, mezclando cobre y estaño, se consigue que los modos de relación resultantes - aunque mantengan las propiedades físicas y químicas de sus componentes - pongan de manifiesto propiedades mecánicas que no estaban antes: dureza, ductilidad, tenacidad...

11. Le llamamos «categorías modales» en la medida en que nos permiten aprehender algo «de un modo determinado». Así por ejemplo podemos pensar en las inteligencias múltiples de Howard Gardner de modo repertorial, en la medida en que forman un conjunto internamente tramado... o de modo disposicional en la medida en que nos fijamos en los detalles del despliegue de una sola de ellas sin relación con las demas. Esto es lo repertorial y lo disposicional no aluden a «objetos» diferentes, aluden a los mismos objetos «de diferente modo». Al contrario de lo que suele suceder con los pares de categorías de contenido (orgánico - inorgánico) los juegos de categorías modales no son excluyentes. 
Podíamos juzgar lo exhaustivo y oportuno de los repertorios, lo pujante y variado de las disposiciones y el nivel de hostilidad o complicidad que el modo de relación en cuestión iba a encontrar en el paisaje. Podíamos comparar diferentes modos de relación, indagar sus fortalezas y debilidades, sus rigideces y sus inestabilidades, sus posibles alianzas con otros...

Así pertrechados le pudimos dar un buen repaso ${ }^{12}$ —de Hamlet a Clint Eastwoo- a cómo nuestra modernidad nos había construido como desacoplados, exiliados modales cuyos repertorios — como el de los indios o el del bueno de Hamlet - habían sido sistemáticamente expoliados dejándonos a merced de lo que pudiéramos improvisar con nuestras ricas o pobres disposiciones y dejando de paso el antiguo mundo de valores y referencias fiables por completo fuera de quicio.

En términos de pensamiento estético la cosa tampoco estaba nada mal, puesto que nos permitía afrontar la historia de las ideas estéticas con una cierta amplitud de miras. Nuestro juego categorial nos permitiría abarcar, casi se diría abrazar, por igual a estéticas reposadas, conservadoras y a estéticas experimentales, a poéticas comprometidas con su contexto socio-político y a poéticas empeñadas en sus propias derivas formales. Todas ellas no sólo resultaban pensables como otras tantas modulaciones de ese equilibrio modal, sino que incluso en cierto modo se necesitaban unas a otras, se reclamaban - como el polo norte necesita al polo sur — para poder hacer su quehacer.

Pero aunque todo eso estaba muy bien, aún nos quedaban muchas cuestiones pendientes. Por ejemplo, no sabíamos por qué ni de qué manera un modo de relación mutaba y pasaba de ser una instancia viva de inteligencia y sensibilidad a convertirse en una rutina acartonada... o cómo lo que había sido una exploración gozosa y fértil de variaciones — como había sucedido con las vanguardias - se convertía en un juego cansino y cínico: ¿cómo se pasaba sin despeinarse de Marcel Duchamp a Jeff Koons? Podíamos explicar la constitución de los modos de relación en función de los variables equili-

12. Ejem, momento publicitario ineludible: para eso está «Desacoplados» que en su segunda edición - con una preciosa portada doble - ya incorpora el ensayo de Hamlet. Vease Claramonte, Jordi: Desacoplados, Editorial unED, Madrid. 2015. 
brios entre repertorios y disposiciones, entre lo que da coherencia y lo que aporta variación, pero si queríamos dar cuenta del devenir de los modos de relación nos harían falta más piezas...

Y tendrían que ser piezas conceptuales de esas que Nicolai Hartmann llamaba de «gran estilo».

Y fue precisamente gracias a Hartmann que nos enganchamos con la ontología modal y la Escuela de Megara. ${ }^{13}$

Esta escuela —en abierta oposición a Platón y Aristóteles - había trabajado la panoplia completa de los modos del ser: necesidad y contingencia, posibilidad e imposibilidad, efectividad e inefectividad, vinculándolos entre ellos y tramando así toda una teoría del cambio que parecía mucho más potente que el juego entre potencia y acto que era lo más parecido que ofrecía la lógica y la ontología aristotélica.

Para entendernos y sin darle muchas vueltas, ${ }^{14}$ el modo de lo necesario alude a aquello que tenemos que hacer, el de lo posible a lo que podemos hacer y el de lo efectivo a lo que de hecho hacemos...

A su vez, estaban los modos negativos. Con lo contingente aparecía lo que no teníamos por qué hacer, con lo imposible lo que no podíamos hacer y con lo inefectivo lo que no hacíamos o incluso lo que dejábamos de hacer.

Entre otras cosas maravillosas, lo que estas tres parejas de modos conseguían era desdoblar cada una de las tres categorías que habíamos definido al estudiar el procomún estético.

13. Megara que ahora es un barrio de Atenas, fue en su momento una pujante polis que se atrevió a desafiar el imperialismo aristocrático de Atenas y lo hizo no sólo en un plano político y militar (en el que fue derrotada) sino también un plano intelectual (en el que fue convenientemente olvidada). Pueden verse algunas de sus implicaciones en Hartmann, Nicolai: Möglichkeit und Wirklichkeit, Walter de Gruyter, Berlin, 1966.

14. Esas «vueltas» constituyen el objeto de mi libro «Estética modal» que a Noviembre de 2015 está aun en proceso de revisión... 
Necesidad y contingencia aparecían entonces como sendos momentos modales ${ }^{15}$ de la categoría de la repertorialidad. Al decir de algo que era necesario, que era algo que teníamos que hacer, no se trataba de pensar que hubiera una especie de mandato de ningún dios barbón o ninguna remota moral abstracta... estábamos asumiendo que ese algo era necesario porque era requerido para dar coherencia y compleción a un repertorio... porque todos los pasos que habíamos dado parecían llamar a ese otro paso que venía a completar, a redondear aquel repertorio con el que estábamos jugándonos los cuartos.

Por las mismas, decíamos de algo que era contingente, que no teníamos por qué hacerlo, si nos parecía que era repertorialmente irrelevante, si sólo añadía ruido al conjunto de referencia... o — lo que podía ser mucho más desolador - si comparecía aislado y sin tramar relaciones de ningún tipo con otros elementos de su misma escala.

A su vez, lo posible y lo imposible aparecían como sendas modulaciones de la categoría de lo disposicional. Para Megara posible era aquello para cuyo cumplimiento podíamos reunir todas y cada una de las condiciones: eso era estrictamente lo que podíamos hacer, lo que estaba en nuestros poderes, al alcance de nuestras disposiciones. Imposible en cambio, era aquello que no podíamos abordar, lo que no estaba a nuestro alcance.

Por supuesto - y esto habrá que tenerlo muy presente - los modos se llaman modos porque no son fases ni regímenes excluyentes. Una acción podíamos comprenderla a la vez como necesaria e imposible, como algo que tenemos que hacer pero que advertimos que no podemos hacer porque nos faltan las disposiciones adecuadas - y ahí duele-.

15. Importante: un momento modal no es un momento tal cual, no es un instante en una serie irreversible. Un momento modal es una decantación - entre otras - de un equilibrio, una forma de orden a través de las fluctuaciones - como planteara Ilya Prigogine- en que se dejan ver los diferentes modos de relación, que como buenas estructuras disipativas se hallan en constante intercambio con el medio. De esto hablaremos con mucho más detalle más adelante. Puede revisarse la fuente en Prigogine, Ilya: The end of Certainty, Simon and Schuster, New York, 1997. 
Otra podía aparecer — como tantas cosas que vemos en los museos- a la vez como imposible y contingente: algo que no había por dónde coger y que de hecho ni siquiera teníamos por qué coger... La cosa daba juego.

Y ese juego - lo vimos pronto - tenía unas reglas que había que investigar. Así había que tener presente lo que Hartmann ${ }^{16}$ llamaba la «Ley modal fundamental» — nada menos — según la cual los modos de lo necesario/contingente y los de lo posible/imposible sólo podían decirse respecto de los modos de lo efectivo/inefectivo.

Estos modos - lo efectivo y lo inefectivo - desdoblaban la categoría de paisaje, especificaban lo que — con independencia de su ser necesario o posible - de hecho se estaba dando o bien había dejado de darse. Sin los modos de lo efectivo/inefectivo perdíamos pie. Y, por supuesto, sin los demás modos perdíamos la cabeza.

Y claro está: ni una cosa ni la otra eran plan. Para volver donde habíamos comenzado había que combinarlos, había que hacer aleaciones, «modos de relación». Ése era el campo que teníamos que investigar, el de las leyes y las relaciones intermodales. Si afinábamos ahí —ésa era y sigue siendo nuestra apuesta - algunos de los más insidiosos problemas y malas inteligencias de la historia del pensamiento estético aparecerían bajo otra luz y más de uno se disolvería como un azucarillo en la lengua de un caballo.

\section{Referencias}

Alexander, Сн. (1977): A pattern language, Oxford University Press, New York. Arendt, H. (2013): The human condition, University of Chicago Press, Chicago. Aristóteles (2012): Metafisica, Random House, Buenos Aires.

BERger, J. (2008): Ways of seeing, Penguin, London.

Claramonte, J. (2010): La República de los fines, cendeac, Murcia .

- (2011): Arte de Contexto, Nerea, Donostia.

- (2015): Desacoplados, Editorial unED, Madrid.

De Certeau, M. (1990): L'invention du quotidien, Arts de faire, Gallimard, Paris.

16. Hartmann, Nicolai: Möglichkeit und Wirklichkeit, Walter de Gruyter, Berlin, 1966. 
Deleuze, G. y C. Parnet (1989): Dialogues, Columbia University Press, New York.

GARDNER, H. (2006): Multiple intelligences, Basic Books, New York.

Hartmann, N. (1983): Aesthetik, Walter de Gruyter, Berlin.

- (1966): Möglichkeit und Wirklichkeit, Walter de Gruyter, Berlin.

LuKács, G. (1966): Estética, Grijalbo, Barcelona.

Morawski, S. (1977): Fundamentos de Estética, Península, Barcelona.

Prigogine, I. (1997): The end of Certainty, Simon and Schuster, New York. 